\title{
Sustainable development goals and universal health coverage: solidarity and equity for all patients
}

\author{
Kawaldip Sehmi \\ International Alliance of Patients' Organizations, London, UK
}

\begin{abstract}
Patient voice is a very important change agent in health policy and health system design. The International Alliance of Patients' Organisations is a non-governmental organisation officially connected with the World Health Organisation, whose vision is to see patients at the centre of healthcare throughout the world.
\end{abstract}

KEY WORDS: global health, health inequalities, health policy.

ADDRESS FOR CORRESPONDENCE: Kawaldip Sehmi, International Alliance of Patients' Organizations, 49-51 East Road London, N16AH United Kingdom, e-mail: kawaldip@iapo.org.uk

The International Alliance of Patients' Organisations is a non-governmental organisation officially connected with the World Health Organisation, whose vision is to see patients at the centre of healthcare throughout the world, and its mission is to build patient-centred healthcare worldwide. Registered in the UK as a charity, the organisation has 276 members in 71 countries, many in low and middle-income countries, and covers over 51 disease areas.

Patient Solidarity Day (PSD), $3^{\text {rd }}$ December 2016, saw patient organisations and advocates all over the world marching out and advocating the implementation into their national health services and programmes of the United Nations Sustainable Development Goal 3 (SDG 3): Ensure healthy lives and promote well-being for all at all ages.

Adopted in September 2015 by 193 Heads of State of the UN General Assembly Members, Resolution 70/1 Sustainable Development Goals 2030 (SDG 2030) is an important development in global health. For the first time, health is placed at the heart of development, and a comprehensive set of targets has been given, to address not only health but also social determinants of health [1].

SDG 3.8 is the flagship health goal. It is about setting up universal health coverage (UHC): all people should receive the health services they need without suffering financial hardship when paying for them, and without discrimination. The UHC should cover the full spectrum of essential and quality health services including health promotion, prevention and treatment, rehabilitation, and palliative care.

In a high-level commitment, each Head of State has promised to achieve all the 17 health and socioeconomic goals within their borders by 2030 through the participation of the whole-of-government, whole-of-society, whole-of-industry (including Pharma), and whole-ofthe patient movement.

\section{SDG 2030 AND HEALTH INEQUALITY}

Professor Michael Marmot, who has led international research on health inequalities for over 30 years, has identified social determinants of health as a major factor responsible for much of the global health inequality and inequity today [2].

Patient organisations welcomed the 17 SDG 2030 goals as they looked at health holistically. Patients' access to education, jobs, and safe environments was as important as their access to universal health coverage.

Patient participation, transparency, accountability, equity, and equality within the health system aim to ensure that UHC delivers on its promises: that health care services, pharmaceuticals, and health goods are available in sufficient quantity, and that they are accessible, acceptable, and affordable and meet international quality and safety standards. 


\section{WHO FRAMEWORK FOR INTEGRATED AND PEOPLE-CENTRED HEALTH CARE AND HEALTH SYSTEM STRENGTHENING FOR UHC}

Many low- and middle-income countries (LMICs) need not only health financing arrangements (national insurance schemes and fiscal measures), but also health system strengthening to achieve UHC [3].

The WHO has proposed that we need to create integrated and people-centred health systems to support the emergent UHCs. In their framework, they propose that every country must do the following [4]:

- Empower and engage people and communities to participate within their health systems. Communities should co-produce healthy environments, provide care services in partnership with the state and non-state health sector, and contribute to healthy public policy.

- Strengthen governance and accountability of health systems by improving policy dialogue, policy formulation, and evaluation in partnership with communities and other stakeholders. Also, they should increase participation, transparency, and accountability in health policy and decision-making. Investment in health informatics and communications technologies is critical.

- Reorienting the model of care is a radical rethinking and restructuring strategy, moving away from traditional approaches. It is about prioritising primary and community care services and the co-production of health. It is about looking at holistic and comprehensive care, including health promotion and ill-health prevention strategies that support people's health and well-being.

- Coordinating services within and across sectors is a strategy coordinating care around the needs and preferences of people at every level of care and integrating it in seamless pathways. It is about improving the delivery of care through the alignment and harmonisation of the processes of the different services.

- Creating an enabling environment involves bringing together the different stakeholders to undertake transformational change through changes in legislative frameworks, financial arrangements, and incentives and the reorientation of the workforce and public policy-making.

\section{ESSENTIAL MEDICINES AND UHC}

The Lancet Commission on Essential Medicines for Universal Health Coverage issued a report in November 2016. They recognised that achieving UHC is heavily dependent on equity and equality of access to medicines. They proposed five strategies [5]:

1. Governments and international donors must finance and support a comprehensive basket of essential medicines to underpin UHC in low- and middle-income countries.
2. Governments and their regulatory and enforcement agencies must assure the quality and safety of medicines globally.

3. Governments, patients, and society must promote the quality use of medicines globally.

4. Governments, pharmaceutical companies, and academies must develop the missing essential medicines.

5. Governments, pharmaceutical companies, and international donors must make essential medicines affordable.

\section{SOCIAL COHESION AND UHC}

Lessons learnt from the setting up of the British National Health Service in 1948 (now the oldest surviving UHC) showed that a UHC has a democratising and a social cohesive effect on the population. A UHC creates a social contract between the state and its citizens. The state, by taking steps towards UHC, also takes steps towards equity, social inclusion, and cohesion.

SDG 2030 anticipates this in goal 10: to reduce inequalities and promote peace, and in goal 16: to provide justice and strong institutions.

\section{SDGS LEAVING NO ONE BEHIND: ALL FOR ONE,} ONE FOR ALL

For the first time, we have a global opportunity for patient advocates to work with hundreds of other stakeholders and communities to achieve SDG 2030. Let us leave no-one behind.

\section{DISCLOSURE}

Author reports no conflict of interest.

\section{References}

1. WHO Transforming our world: the 2030 Agenda for Sustainable Development. Available from: http://bit.ly/1Epf648 (accessed 25 October 2016).

2. Marmot M. The health gap: the challenge of an unequal world. Bloomsbury, London 2015.

3. WHO Framework for action: Strengthening health system to improve health outcomes 2007. Available from: http://bit.ly/ 1tOicdj (accessed 25 October 2016).

4. WHO Framework on integrated and people-centred health care. Available from: http://bit.ly/1xFqNWt (accessed 25 October 2016).

5. Wirtz VJ. Essential medicines for universal health coverage. Available from: http://bit.ly/2feQ19l (accessed 25 October 2016). 